Article

\title{
Spatiotemporal Variation in Full-Flowering Dates of Tree Peonies in the Middle and Lower Reaches of China's Yellow River: A Simulation through the Panel Data Model
}

\author{
Haolong Liu ${ }^{1}$, Junhu Dai ${ }^{1}$ and Jun Liu ${ }^{2, *}$ \\ 1 Key Laboratory of Land Surface Pattern and Simulation, Institute of Geographic Sciences and Natural \\ Resources Research, CAS, Beijing 100101, China; liuhl@igsnrr.ac.cn (H.L.); daijh@igsnrr.ac.cn (J.D.) \\ 2 Tourism School, Sichuan University, 24 South Section 1 Ring Road No. 1, Chengdu 610065, China \\ * Correspondence: liujun_igsnrr@126.com
}

Received: 15 June 2017; Accepted: 28 July 2017; Published: 1 August 2017

\begin{abstract}
The spring flowering of tree peony (Paeonia suffruticosa) not only attract tens of million tourists every year, but it can also serve as a bio-indicator of climate change. Examining climate-associated spatiotemporal changes in peony flowering can contribute to the development of smarter flower-viewing tourism by providing more efficient decision-making information. We developed a panel data model for the tree peony to quantify the relationship between full-flowering date (FFD) and air temperature in the middle and lower reaches of China's Yellow River. Then, on the basis of the model and temperature data, FFD series at 24 sites during 1955-2011 were reconstructed and the spatiotemporal variation in FFD over the region was analysed. Our results showed that the panel data model could well simulate the phenophase at the regional scale with due consideration paid to efficiency and difficulty, and the advance of peony FFD responded to the increase in February-April temperature at a rate of 3.02 days $/ 1^{\circ} \mathrm{C}$. In addition, the simulation revealed that regional FFDs followed the latitudinal gradient and had advanced by 6-9 days over the past 57 years, at the rate of 0.8 to 1.8 days/decade. Among sub-areas, the eastern forelands of Taihang Mountains and Luliang Mountains showed more FFD advances than the other areas.
\end{abstract}

Keywords: tree peony; full-flowering date; panel data model; spatiotemporal variation; climate change; smarter tourism; decision-making information

\section{Introduction}

Phenological events, which are independent of instrumental records, could serve as bioindicators of climate change [1,2]. Numerous studies in Europe and North America indicated that spring phenophases have advanced to various extents at mid- and high latitudes in recent decades [3-5]. Similar conclusions were also made in Chinese literature [6-8]. These studies also provided insight into how future climate changes may manifest in biological systems. Among these studies, ornamental plants and economic plants in China have received a few attention (e.g., [9-11]). However, most of related studies were still on local scales. By comparison, scaling phenology from the local to the regional level has been an international trend in oversea studies $[12,13]$. Therefore, further phenological investigations on the two kinds of plants in China are still necessary [14].

Tree peony (Paeonia suffruticosa) is one of the most attractive native ornamental plants in China (Figure 1A). Furthermore, it is also an important economic plant with medicinal and oil-utilized values, which is especially attractive to elderly and female tourists. In 2017, the peony festival in Luoyang alone attracted about 24.94 million tourists and generated 22.35 billion RMB incomes. Nevertheless, the related seasonal tourism is vulnerable to climate changes. The starting dates of peony festival in 
Luoyang has advanced from April 15 to April 5 in recent 30 years, due to the impact of global warming. In addition, the festival date, which was decided by reference to the spring phenophases of the last year, sometimes occurs a little earlier or later than the actual flowering. As a result, tourists may not happen to travel in the best flower-viewing period for tree peonies, making a potential negative effect on visiting experiences. Disappointing visiting experiences have been proved to restrain tourist spending [15] and discourage tourists from revisiting [16]. Therefore, in order to increase the economic and social efficiency of the flower-viewing tourism, related designs of landscape and travel route need more spatiotemporal knowledge of florescence than ever.

At present, the actual observation data on peony florescence are lacking in many places of China. Considering that phenological models are the only method that can project into the future or reconstruct the past [17], we utilized a new kind of phenological model—the panel data model—to quantify the relationship between temperature and full-flowering date (FFD), and reconstructed the spatiotemporal variation in peony FFD in stations. The applications of this model for phenological studies in China have not been reported, but it can also provide a good accuracy in prediction like the process-based model. In the meantime, it is simpler to set up than the process-based model. The reconstructed spatiotemporal variation in peony FFD upscaled peony phenology from the single site to the larger region, and extrapolated the results to the time period beyond the actual observation. This study will not only contribute to our understanding of peony phenology changes during 1955-2011 which were unknown in the past, but also provide insight into how peony florescence will response to the future climate changes. It could provide the flower-viewing tourism with a scientific basis on its adaptation and mitigation policies that aim to lessen the impact of climate change, promote the tourism management and services to be smarter, and enrich tourists experiences.

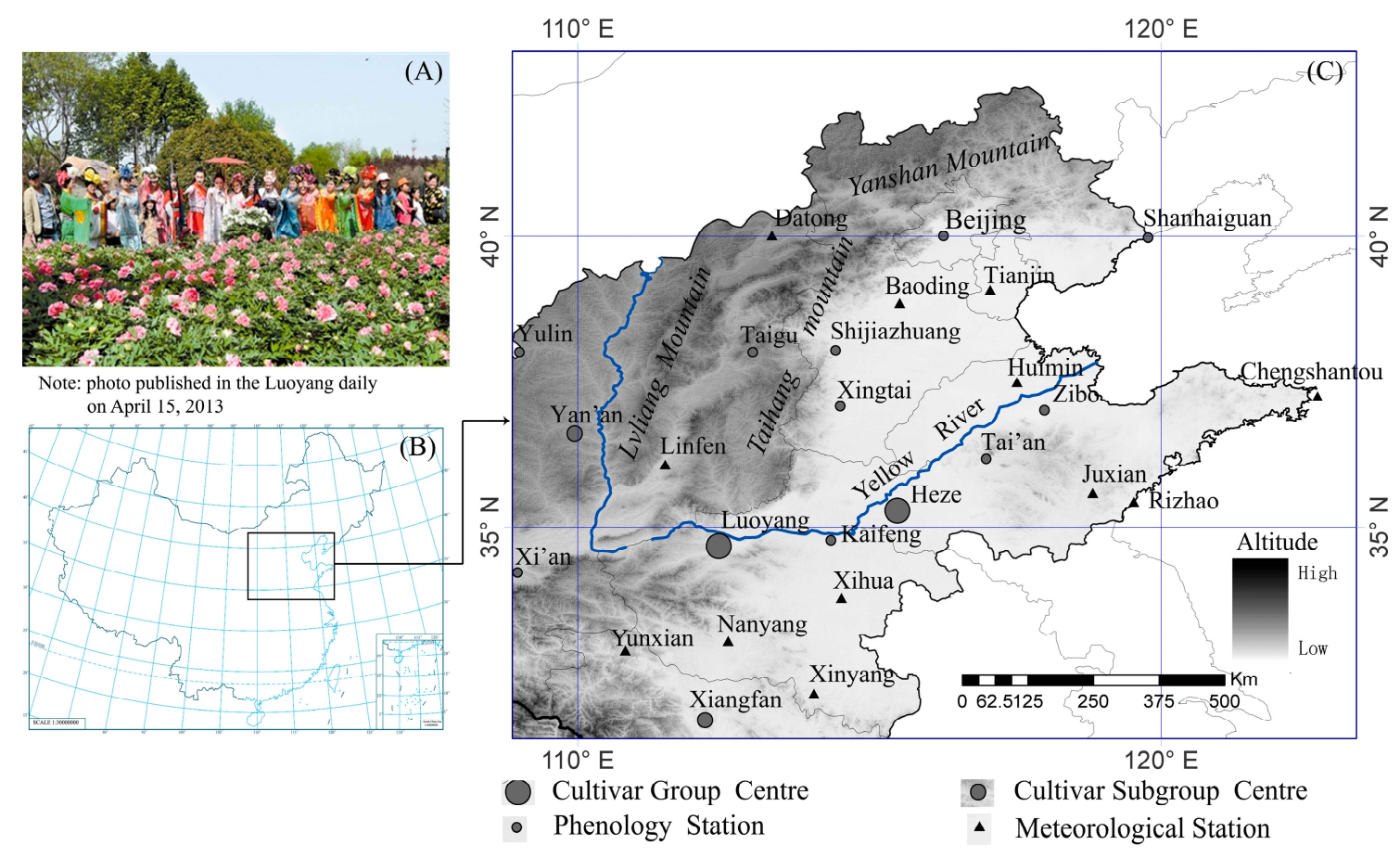

Figure 1. (A) The photograph of peonies viewed by people; (B) the distribution area of Zhongyuan Peony in China; and (C) phenological and meteorological observation stations.

\section{Materials and Methods}

\subsection{Phenological and Meteorological Data}

Twelve phenological data sets in the middle and lower reaches of the Yellow River (Figure 1B,C) were used in this study to analyze the spatiotemporal variation in peony FFD. This choice was 
made because the most famous cultivar group of tree peonies in China-Zhongyuan Peony-is traditionally grown in this warm-temperate region [18]. Two hundred and twenty observations were collected from1963 to 2011. The geographic location and observations of each station were provided in Table 1. In addition to date series from Heze and Shijiazhuang as well as Kaifeng, most of the other observations are derived from the China Phenological Observation Network (CPON), which is a nationwide system of phenological monitoring. Date series from Heze were mainly picked out from the previous literatures [19-21], while those from Shijiazhuang were obtained from the Shijiazhuang phenological data platform. Some reports in local newspapers also contributed 45 observations to data sets. All the observations conformed to the same standard of full flowering: at least $50 \%$ of flowers are in full bloom [22].

Table 1. The summary of peony FFD dataset at each station.

\begin{tabular}{cccccc}
\hline Station & Province & Location & $\begin{array}{c}\text { Elevation } \\
\text { (ma. s. 1.) }\end{array}$ & Period & Observations \\
\hline $\begin{array}{c}\text { Beijing } \\
\text { Shanhaiguan }\end{array}$ & Beijing & $40^{\circ} 01^{\prime} \mathrm{N}, 116^{\circ} 20^{\prime} \mathrm{E}$ & 116 & $1963-2011$ & 40 \\
Shijiazhuang & Hebei & $40^{\circ} 02^{\prime} \mathrm{N}, 19^{\circ} 44^{\prime} \mathrm{E}$ & 45 & $1967-1972$ & 6 \\
Xintai & Hebei & $38^{\circ} 01^{\prime} \mathrm{N}, 114^{\circ} 25^{\prime} \mathrm{E}$ & 84 & $1983-2008$ & 15 \\
Kaifeng & Henan & $37^{\circ} 04^{\prime} \mathrm{N}, 114^{\circ} 30^{\prime} \mathrm{E}$ & 77 & $1985-1996$ & 12 \\
Luoyang & Henan & $34^{\circ} 46^{\prime} \mathrm{N}, 114^{\circ} 20^{\prime} \mathrm{E}$ & 25 & $2006-2010$ & 5 \\
Xi'an & Shaanxi & $34^{\circ} 10^{\prime} \mathrm{N}, 112^{\circ} 25^{\prime} \mathrm{E}$ & 138 & $1964-2011$ & 43 \\
Yulin & Shaanxi & $38^{\circ} 14^{\prime} \mathrm{N}, 108^{\circ} \mathrm{E} 4^{\prime} \mathrm{E}$ & 438 & $1963-2011$ & 35 \\
Heze & Shandong & $35^{\circ} 17^{\prime} \mathrm{N}, 115^{\circ} 29^{\prime} \mathrm{E}$ & 55 & $1965-1966$ & 2 \\
Tai'an & Shandong & $36^{\circ} 10^{\prime} \mathrm{N}, 117^{\circ} 01^{\prime} \mathrm{E}$ & 155 & $1963-2011$ & 49 \\
Zibo & Shandong & $36^{\circ} 53^{\prime} \mathrm{N}, 118^{\circ} 14^{\prime} \mathrm{E}$ & 33 & $1982-1989$ & 8 \\
Taigu & Shanxi & $37^{\circ} 30^{\prime} \mathrm{N}, 112^{\circ} 37^{\prime} \mathrm{E}$ & 796 & $1964-1967$ & 2 \\
\hline
\end{tabular}

To construct and evaluate the panel data model, we used mean monthly temperatures data of 1963-2011 from $12 \mathrm{cs,}$ which are located nearby the above phenological stations. After the model validity test, temperatures data from other 12 meteorological stations (Figure 1C) were used to reconstruct FFD series in the study area. All meteorological data were obtained from the China Meteorological Data Sharing Service System (http://cdc.cma.gov.cn/).

\subsection{Methods}

\subsubsection{Model Construction}

The term "panel data" refers to the pooling of observations on a cross-section of individuals over several periods [23]. The regional data on the FFD of Zhongyuan Peony and its climate factors are fully consistent with the essential trait of panel data sets. According to the biometrics and statistics literature, panel data sets possess many advantages over conventional cross-sectional or time-series data sets [24]. For example, panel data can give more variability, more degrees of freedom and more estimate efficiency. Remarkably, this model can control individual heterogeneity, whereas time-series and cross-section studies may run the risk of obtaining biased results, e.g., see $[25,26]$. Panel data models haven't been widely applied in the phenological field, so we tried this new approach to peony FFD.

The subject we are interested in is the quantitative relation between the annual FFDs of tree peonies $\left\{Y_{i t}\right\}$ and the related temperature factor $\left\{X_{i t}\right\}$. Here, $Y_{i t}$ was measured as days of deviation from 23 April (same as below), which is the mean value of all FFD data in the distribution area during 1963-2011. For the Zhongyuan peonies, the temperature condition during February-April is the predominant factor controlling FFD (e.g., $[18,19])$. Thus, February-April mean temperature was selected as the only input variable of the model. Aim to construct a uniform model which 
can be extrapolated to any station and time period, a linear regression with variable intercepts was constructed. The function can be written as the following form:

$$
Y_{i t}=\alpha+\beta X_{i t}+u_{i t}
$$

where $\alpha$ is a scalar, $\beta$ is a constant, $X_{i t}$ is the explanatory variable (February-April mean temperature) in the year $t$ at the station $i$. The error term, $u_{i t}$, represents the effects of those omitted variables that are peculiar to both the individual stations and time periods. Ideally, individual-specific effect and the remainder disturbance, say $\mu_{i}$ and $v_{i t}$, should be explicitly introduced into omitted variables. Thus, $u_{i t}$ can be written as:

$$
u_{i t}=\mu_{i}+v_{i t}
$$

As for this model, parameter estimators are different under three premise conditions. Under the first assumption, the sub-model is called pooled model, whose $\mu_{i}$ and $v_{i t}$ are identically zero for all $i$ and $t$. Ordinary-least-squares (OLS) estimation is appropriate for it. Under the second one, the sub-model is called fixed effects model. In the function, $\mu_{i}$ are fixed parameters and the stochastic $v_{i t}$ are independent and identically distributed. Least-squares dummy-variable (LSDV) estimation is the more proper approach. Under the last one, the sub-model is called random effects model. $\mu_{i}$ and $v_{i t}$ are both random, and $X_{i t}$ are independent of $\mu_{i}$ and $v_{i t}$, for all $i$ and $t$. Generalized-least-squares (GLS) estimation is its optimization algorithm. Hsiao elaborated on the relevant details and assessed the corresponding parameter estimation efficiencies [24].

In order to reduce or avoid the omitted-variable bias as much as possible, the redundant fixed-effects test and Hausman test are often used to find out the most appropriate model form [22-26]. The former can confirm that if the fixed-effects assumption was more appropriate than the pooled assumption. The latter helps to choose between the model with fixed effects and the one with random effects. This paper employed the EViews software to run all the related tests and estimate the model parameters.

\subsubsection{Model Validity Test}

The double cross-validation was used to test the robustness of this model. Samples were firstly split into two subsets during different periods: 1963-1987 and 1988-2011. Then, the calibration equation was constructed with the training set in 1963-1987 by using the LS estimator, while the validation set in 1988-2011 was leaved out to test the generalization ability of the derived model. Four statistics were used to measure the fractional variance between actual and reconstructed FFDs. Among them, the calibration validity was measured by the determination coefficient (square of correlation coefficient, $R^{2}$ ) and the root-mean-square error (RMSE, Equation (3)), and the verification validity was measured not only by the $\mathrm{R}^{2}$ and RMSE, but also by the reduction of error (RE, Equation (4)), and the coefficient of efficiency (CE, Equation (5)). In the final step, switching the subset in 1988-2011 as the calibration data and another subset in 1963-1987 as the verification data, the same tests were run.

$$
\begin{gathered}
\text { RMSE }=\sqrt{\frac{\sum\left(x_{i}-\hat{x}_{i}\right)^{2}}{n}} \\
\mathrm{RE}=1.0-\frac{\sum\left(x_{v_{i}}-\hat{x}_{v_{i}}\right)^{2}}{\sum\left(x_{v_{i}}-\bar{x}_{c}\right)^{2}} \\
\mathrm{CE}=1.0-\frac{\sum\left(x_{v_{i}}-\hat{x}_{v_{i}}\right)^{2}}{\sum\left(x_{v_{i}}-\bar{x}_{v}\right)^{2}}
\end{gathered}
$$

where $x_{i}$ and $\hat{x}_{i}$ are the observed and simulated data in $i$ year of the calibration period or the verification period, $x_{v_{i}}$ and $\hat{x}_{v_{i}}$ are the observed and simulated data in $i$ year of the validation period, $\bar{x}_{c}$ is the mean observed FFD in the calibration period, and $\bar{x}_{v}$ is the mean observed data in the validation period. 


\subsection{Spatiotemporal Variation Analysis of Simulated Peony FFDs}

We took five steps to analyse the spatiotemporal variation in the regional peony FFDs. Firstly, on the basis of the panel data model, annual FFDs in 1955-2011 were reconstructed for all phenological and meteorological stations. Secondly, the 57-year mean values of every reconstructed FFD series were calculated. Thirdly, their contour distribution was derived by the Kriging interpolation. Fourthly, a linear regression between FFDs and years was used to evaluate the temporal trends and calculate the accumulated advance in FFD for each station. Finally, the spatial pattern of accumulated advances in FFD over the study area was analysed by use of ArcGIS.

\section{Results}

\subsection{Optimised Parameters Estimation}

According to the principle of the above-mentioned tests [23,27], the fixed effects model is superior to the pooled model, because the $p$-value of redundant fixed-effects test is smaller than 0.05 (Table 2). In meanwhile, the random-effects model is better than the fixed-effects model, because of the $p$-value larger than 0.05 yielded by the Hausman test (Table 3).

Table 2. The result of redundant fixed-effects test.

\begin{tabular}{cccc}
\hline Effects Test & Statistic & d. f. & Prob. \\
\hline Cross-section F & 7.035 & $(11,207)$ & 0.000 \\
Cross-section Chi-square & 69.868 & 11 & 0.000 \\
\hline
\end{tabular}

Table 3. The result of Hausman test.

\begin{tabular}{cccc}
\hline Test Summary & Chi-Sq. Statistic & Chi-Sq. d. f. & Prob. \\
\hline Cross-section random & 0.016 & 1 & 0.899 \\
\hline
\end{tabular}

After the random-effects model was identified as the optimal choice, we fitted the model by the GLS estimation. Estimated parameters and statistical indicators of the model accuracy were provided in Table 4. Among them, the $\mathrm{R}^{2}$ is as high as $0.680(p<0.001)$ and the RMSE is 3.037. The equation of this unified model for FFD predicting across the region can be written as:

$$
Y_{i t}=24.406-3.018 \times X_{i t}
$$

From the equation, we can know that the advance of regional peony FFD responded to the increase in spring (February-April) temperature at a rate of -3.02 days $/ 1^{\circ} \mathrm{C}$. The predicting values of FFD at each phenological station can be further revised by the corresponding $u_{i t}$.

Table 4. Parameter estimation for the random effects model.

\begin{tabular}{|c|c|c|c|}
\hline Parameter & Fitted Value & Std. Error & Prob. \\
\hline$\alpha$ & 24.406 & 1.192 & 0.000 \\
\hline$\beta$ & -3.018 & 0.139 & 0.000 \\
\hline \multicolumn{4}{|c|}{$u_{i t}$ for individual phenological stations } \\
\hline Beijing & -1.000 & Heze & 0.335 \\
\hline Kaifeng & -0.717 & Luoyang & -2.205 \\
\hline Shanhaiguan & -2.806 & Shijiazhuang & 0.925 \\
\hline Tai'an & -1.323 & Taigu & 0.034 \\
\hline Xi'an & -0.190 & Xingtai & 3.617 \\
\hline Yulin & 2.874 & Zibo & 0.457 \\
\hline \multicolumn{4}{|c|}{ Weighted Statistics } \\
\hline $\mathrm{R}^{2}$ & 0.682 & RMSE. & 3.037 \\
\hline Adjusted $\mathrm{R}^{2}$ & 0.680 & F-statistic & 466.811 \\
\hline Prob. & 0.000 & & \\
\hline
\end{tabular}




\subsection{Model Validity}

The model was satisfactory in terms of four test statistics. First, the determination coefficient indicates that the regression models can explain $70-80 \%$ of the FFD variance (Figure 2). Second, RE and CE over the validation period 1988-2011 are 0.77 and 0.65 , respectively; whereas they are 0.73 and 0.61 for the validation period 1963-1987. According to climatological and hydrological experiences [28-30], both of them being positive indicates high reliability of the derived reconstructions. The medians of $R^{2}$ and $R E$ as well as CE are $0.76,0.75$, and 0.63 , respectively. The decreasing trend in these three statistics follows exactly the expected rigor level of the regression model calibration and validation tests. Last, the median RMSE is 3.62, which indicates the kind of regression model has a good predictive/reconstructive performance. The predicting validity of this model has been proved in biometric and econometrics fields $[23,27]$. Our study further shows that this approach can also provide accurate results for phenological studies.
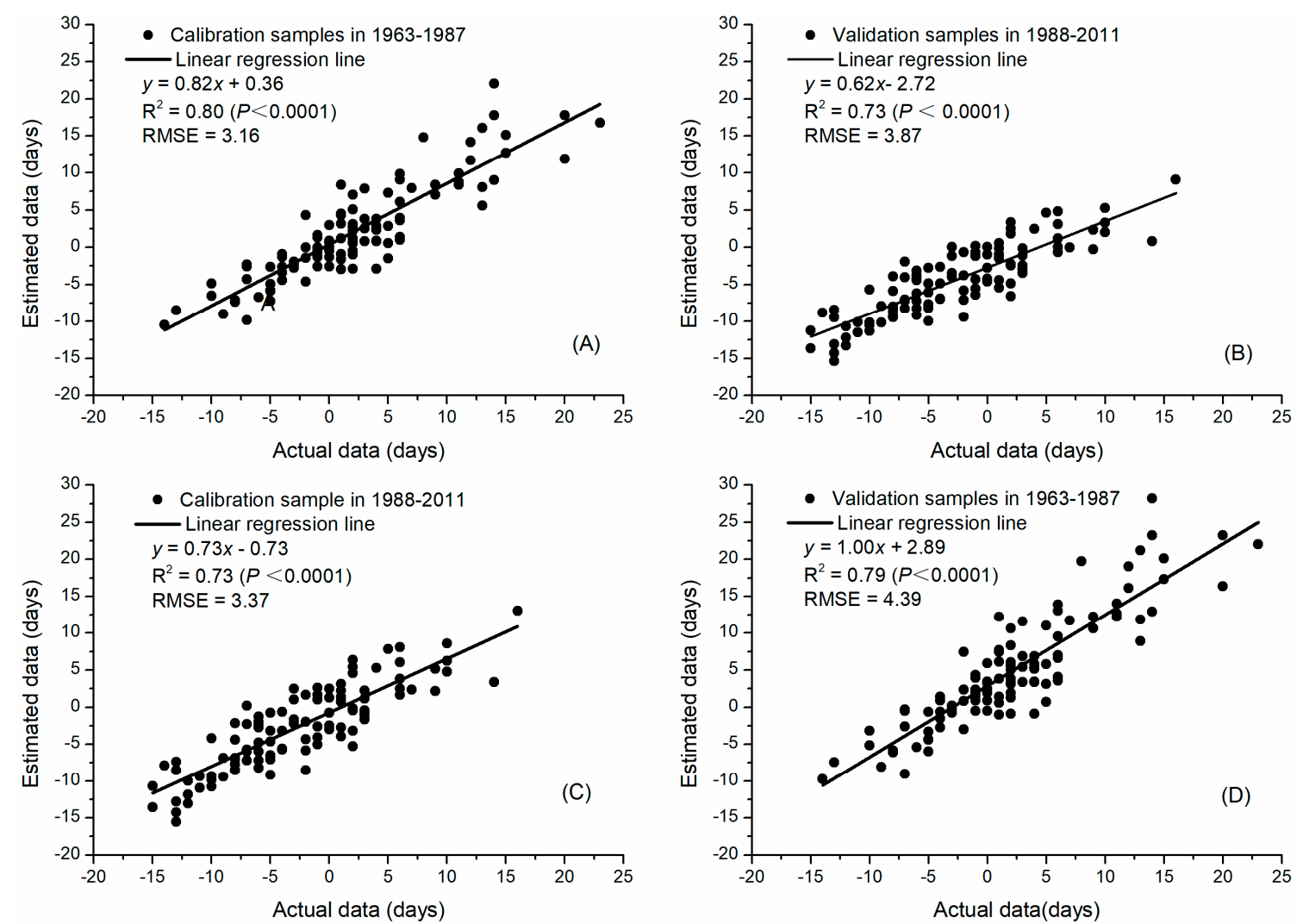

Figure 2. Results of determination coefficient and RMSE for the double cross-validation. (A) 1963-1987 as the calibration period; (B) 1988-2011 as the validation period; (C) 1988-2011 as the calibration period; and (D) 1963-1987 as the validation period. Here, both $x$ and $y$ are in terms of days of deviation from 23 April.

\subsection{Spatial Variations in 57-Year Mean FFD and FFD Trend}

The simulated spatial pattern of 57-year mean FFDs across the study area was shown in Figure 3. The regional FFD gradually became later from south to north with an amplitude of approximately 1 month. The earliest FFD occurred on 15 April in latitude $31^{\circ} \mathrm{N}$, while the latest FFD occurred on 17 May in latitude $40^{\circ} \mathrm{N}$. In addition, the FFD was not strictly linearly increased with latitude, which is more obvious in the northern subarea than in the southern subarea. These results imply that the atmospheric meridional temperature gradient should be the most important controlling factor for the spatial pattern of peony FFDs, while temperature change closely related to impacts of large-scale terrains leads to the zonal spatial heterogeneity of peony FFDs. 
The reconstructed peony FFDs in the study area for 1955-2011 showed significant advance trends. The mean linear trend in the study area was about -1.3 days/decade, varying from -1.8 to -0.8 days/decade $(p<0.001)$ at different phenological stations (e.g., Beijing, Heze, Luoyang, and Tai'an, shown in Figure 4). In general, the study area can be divided into three sub-areas, according to the magnitude of advance over the past 57 years (Figure 5). The first sub-area included Beijing, Tianjin, most parts of Hebei, east of Shanxi, and north of Henan, where the FFD advance was greatest (about 8-9 days). The second sub-area was in east of Shaanxi, west of Shanxi, north of Henan, and west of Shandong, where the advance in FFD was moderate (about 7-8 days). The last one was located in east of Shandong, south of Henan, northwest of Hubei, and southeast of Shaanxi, where the FFD exhibited 6-7 days of advance.

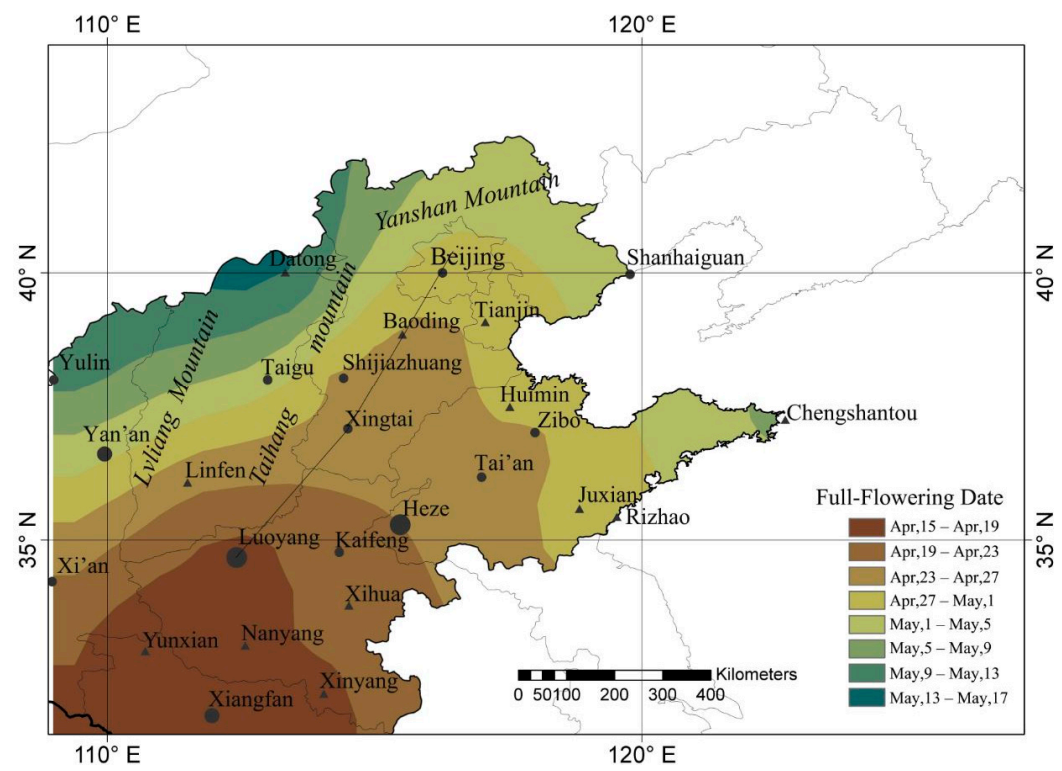

Figure 3. Spatial variation in the 57-year mean FFD for the Zhongyuan peonies.

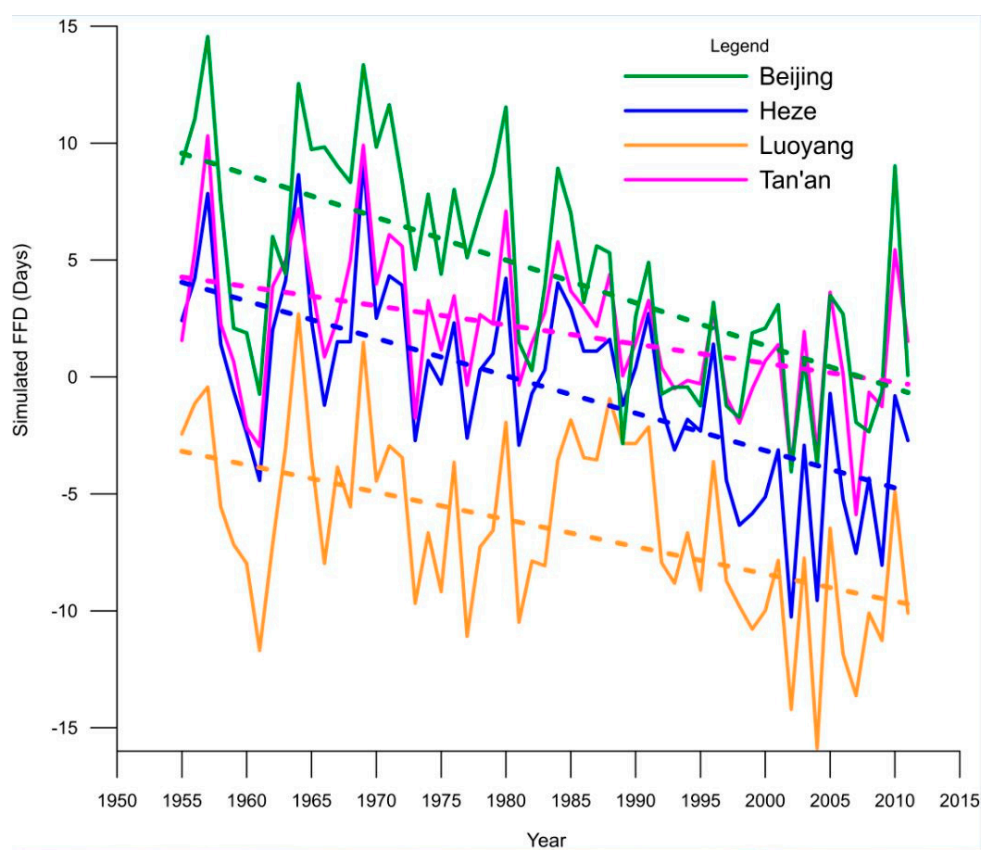

Figure 4. Annual variations of the regional peony FFDs and their linear trends from 1955 to 2011. 


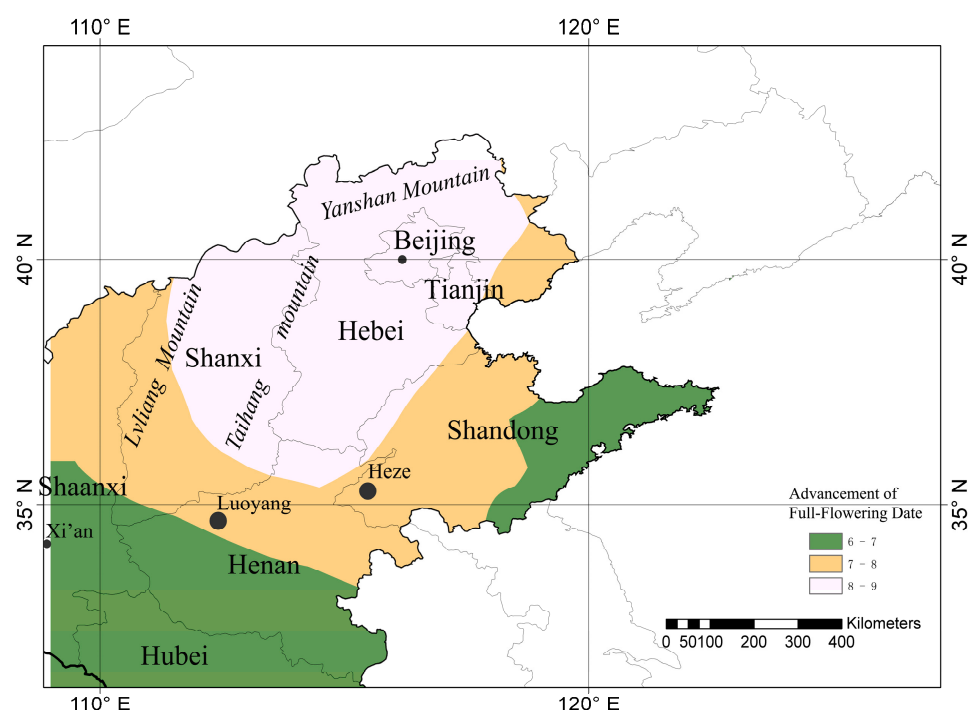

Figure 5. Spatial variation in FFD trend for the Zhongyuan peonies during 1955-2011.

\section{Discussion}

\subsection{Benefits of the Panel Data Model}

The panel data model possesses several major advantages over conventional phenological modelcs. The single-site linear regression model is simple to set up and usually provides accurate results. However, its extrapolation to other regions and time periods may not be robust, especially in extreme conditions. The process-based model can produce a smaller extrapolation error than the former, but it is more difficult to establish. It costs much more time to run simulations, and the simulation effectiveness depends on the algorithm schedule, the choice of initial temperature, and the number of iterations. By comparison, the panel data model can be viewed as a simplified form of the process-based model, according to the cognition that plant growth during the quiescent period is nearly linear [12,31]. It is much more robust than the single-site linear regression model, and easier to establish than the process-based model. More importantly, the two conventional models cannot control the individual heterogeneity and thus run the risk of obtaining biased results. However, by utilizing information on both the intertemporal dynamics and the individuality of the stations being investigated, the panel data model is able to control in a more natural way for the effects of those missing or unobserved variables $[23,24]$.

For the Zhongyuan peonies, spring temperature is the predominant factor controlling FFD, while the precipitation and sunshine duration have no significant influences (e.g., $[18,19])$. Therefore, we constructed a panel data model which has only one explanatory variable-February-April mean temperature. However, for other plant species in China, the precipitation and sunshine duration may need to be considered as the explanatory variables (e.g., [32,33]). Conventional time-series studies in the phenological field are often plagued with the collinearity among explanatory variables. By comparison, panel data models applied to econometric estimates can reduce the collinearity among explanatory variables $[23,24]$. Thus, the panel data model should be expected to have more application in phenological studies.

\subsection{The Consistency of Regional Phenological Trends}

The advanced FFD trend of Zhongyuan Peony was largely consistent with spring phenological changes in other places. For example, over the past 57 years, the advance of peony FFD in Luoyang, Heze, Beijing, and $\mathrm{Xi}^{\prime}$ an was respectively $-1.2,-1.6,-1.8$, and -1.4 days/decade. Another phenological result from [34] was close to this study: trends of the first leaf date (FLD) for Chinese ash 
trees (Fraxinus chinensis Roxb.) over the period 1952-2007 were nearly -1.1 days/decade in Henan, -2.0 days/decade in Beijing and Shandong, and -1.4 days/decade in Shaanxi. Furthermore, the first flowering dates of 23 species at 22 stations in eastern China since the 1960s were found to advance at the average rate of 1.2 days/decade [35], and the same rate has been reported for the FLD across the Northern Hemisphere over the period 1955-2002 [36]. The two results are also in good agreement with the average trend ( -1.3 days/decade) of Zhongyuan Peony. Based on the phenology theory that phenophases of different species in the same climatic zone usually advance or delay synchronously [37], the advanced FFD trend of Zhongyuan Peony can be viewed as a good proxy of the overall mean phenological changes in the warm-temperate zone of China during the recent decades.

\subsection{Influential Factors on Spatial Heterogeneity in FFD}

Peony FFDs in the eastern forelands of Taihang Mountains and Lvliang Mountains showed steeper gradients and clearer advances of than those in the other sub-areas (Figures 3 and 5). These piedmont regions are located in the climate-sensitive area $\left(32^{\circ}-42^{\circ} \mathrm{N}, 110^{\circ}-120^{\circ} \mathrm{E}\right)$ where the strongest advance of FLD has occurred in China during the past 50 years [38]. In addition, these regions belong to the high-risk area of wheat dry-hot wind in northern China [39]. We consider that the foehn caused by mountainous terrain should impose an important influence on the above phenomena. It is well known that the foehn can not only cause the temperature to rise, but also cause the relative humidity to fall on the lee side of a mountain range. Furthermore, the advance of spring phenophases can be prompted by it. In the case of the Taihang Mountains, the foehn area can generally extend $170 \mathrm{~km}$ to the east, and up to $254 \mathrm{~km}$ farther during stronger foehn processes [40]. In general, a foehn area possesses a heat resource as much as the southern areas about 2-3 latitudes away [41]. Beijing, Baoding, Shijiazhuang and Xingtai, where peony FFD showed the strongest advance in the study area, happen to locate in the above-mentioned range.

\subsection{Practical Applications of Phenoloigcal Researches in Tourism}

In China, tourism industry has gradually become a pillar industry and played an important role in the society during the past 30 years. However, there are still some problems which cannot be neglected in the development of tourism, such as inefficient management, low service level, and mismatch with accelerated technological and social developments. In order to regulate and upgrade the traditional tourism, the smarter tourism, inspired by IBM's "Smarter Planet" and "Smarter City", has been put forward as a strategic solution [42]. Our research results can contribute to the development of the smart tourism by providing more efficient and intelligent information. From a perspective of tourism destination, phenological knowledge can help them to first recognise the new challenge arising from changes in both the climate and tourists, and then to proactively respond in terms of landscape planning and tourist management. With phenological information being embedded on tourism organisations and entities, it can also enhance the competitiveness of destinations, support travel agencies to make smarter decision on travel routes, and enrich experiences of tourists and local residents.

Bringing smartness into tourism, especially into tourism destinations, requires phenological studies in China to be more closely connected with the development of tourism industry. Although this paper and some other studies (e.g., [43-45]) has shed some light on the spatiotemporal dynamics of flower-viewing in China, more measures are still needed to expand the contributions of phenology. For example, in most of the time, tourists only have limited knowledge and low awareness on the phenological changes of destinations they visit. Thus, more regional phenological calendars should be updated with the support of observation data and simulation results as soon as possible, and be provided by the tourism service platform of destinations. Furthermore, due to uncertainties in future climate, the risk prediction of phenoloigcal landscapes should combine phenological models with different climate scenarios and related strategies of risk management should also be adapted 
to them. In addition, analyzing the relation between the spatiotemporal changes of tourist flow and phenoloigcal landscapes would be a prosperous field in tourism geography for the future.

\section{Conclusions}

In the present study, a panel data model was utilized to quantify the relationship between the peony FFD and spring temperature, and the spatiotemporal variation in FFD in the middle and lower reaches of China's Yellow River in 1955-2011 was further analyzed on the basis of the model. The following conclusions can be made: (1) the panel data model can well simulate FFDs at the regional scale, with due consideration paid to both efficiency and difficulty; (2) the advance of peony FFD responded to the increase in February-April temperature at a rate of 3.02 days $/ 1^{\circ} \mathrm{C}$; (3) regional FFDs of tree peonies followed the latitudinal gradient and had advanced by 6-9 days over the past 57 years, at the rate of 0.8 to 1.8 days/decade; (4) the eastern forelands of Taihang Mountains and Luliang Mountains showed more FFD advances than the other sub-areas.

Acknowledgments: This research study was supported by the National Natural Science Foundation of China (grant No. 41427805) and the Basic Research Project of the Ministry of Science and Technology (grant No. 2014FY210900 and 2011FY120300]. We also thank three anonymous reviewers and the editor for providing comments and critiques that significantly improved the manuscript.

Author Contributions: Haolong Liu contributed to all aspects of this work; Junhu Dai revised the paper; and Jun Liu analyzed the data and put forward the related suggestions for tourism; all authors reviewed the manuscript.

Conflicts of Interest: The authors declare no conflict of interest.

\section{References}

1. Walther, G.-R.; Burga, C.A.; Edwards, P.J. "Fingerprints" of Climate Change: Adapted Behaviour and Shifting Species Ranges; Kluwer Academic/Plenum Publishers: New York, NY, USA, 2001.

2. Schwartz, M.D. Phenology: An Integrative Environmental Science; Kluwer Academic Publishers: Dordrecht, The Netherlands, 2003.

3. Schwartz, M.D.; Reiter, B.E. Changes in North American spring. Int. J. Climatol. 2000, 20, 929-932. [CrossRef]

4. Parmesan, C.; Yohe, G. A globally coherent fingerprint of climate change impacts across natural systems. Nature 2003, 421, 37-42. [CrossRef] [PubMed]

5. Rosenzweig, C.; Casassa, G.; Karoly, D.J.; Imeson, A.; Liu, C.; Menzel, A.; Rawlins, S.; Root, T.L.; Seguin, B.; Tryjanowski, P. Assessment of observed changes and responses in natural and managed systems. In Climate Change 2007: Impacts, Adaptation and Vulnerability; Parry, M.L., Canziani, O.F., Palutikof, J.P., van der Linden, P.J., Hanson, C.E., Eds.; Contribution of Working Group II to the Fourth Assessment Report of the Intergovernmental Panel on Climate Change; Cambridge University Press: Cambridge, UK, 2007; pp. 79-131.

6. Chen, X.Q.; Zhang, F.C. Spring phonological change in Beijing in the last 50 years and its response to the climatic changes. Chin. J. Agrometeorol. 2001, 22, 1-5.

7. Wu, X.C.; Liu, H.Y. Consistent shifts in spring vegetation green-up date across temperate biomes in China, 1982-2006. Glob. Chang. Biol. 2013, 19, 870-880. [CrossRef] [PubMed]

8. Zhu, L.; Meng, J. Determining the relative importance of climatic drivers on spring phenology in grassland ecosystems of semi-arid areas. Int. J. Biometeorol. 2015, 59, 237-248. [CrossRef] [PubMed]

9. Chen, Z.H.; Xiao, M.; Chen, X. Change in flowering dates of Japanese Cherry Blossoms (P. yedoensis Mats.) on campus of Wuhan University and its relationship with variability of winter temperature. Acta Ecol. Sin. 2008, 28, 5209-5217.

10. Kong, F.Z.; Liu, J.M.; Kong, L.; Zhang, Z.H. Mid and long-term forecast model for the early florescence of Heze Peony. Chin. J. Agrometeorol. 2011, 32, 115-121.

11. Li, X.C.; Tao, H.; Zhang, S.M.; Liu, H.Y. The impact and prediction of climate change on first-flowering date of Korla Fragrant Pear. Chin. J. Agrometeorol. 2012, 33, 119-123.

12. Chuine, I.; Cambon, G.; Comtois, P. Scaling phenology from the local to the regional level: Advances from species-specific phenological models. Glob. Chang. Biol. 2000, 6, 943-952. [CrossRef] 
13. Honjo, H.; Fukui, R.; Sugiura, T.; Aono, Y. The DTS accumulation model for predicting the flowering date of Japanese pear tree in Japan. Acta Hort. 2006, 707, 151-158. [CrossRef]

14. Ge, Q.S. The progress of phenology studies and challenges to modern phenology research in China. Bull. Chin. Acad. Sci. 2010, 25, 310-316.

15. Chhabra, D.; Healy, R.; Sills, E. Staged authenticity and heritage tourism. Ann. Tour. Res. 2003, 30, 702-719. [CrossRef]

16. Poria, Y.; Butler, R.; Airey, D. The core of heritage tourism: Distinguishing heritage tourists from tourists in heritage laces. Ann. Tour. Res. 2003, 30, 238-254. [CrossRef]

17. Cleland, E.E.; Chiariello, N.R.; Loarie, S.R.; Mooney, H.A.; Field, C.B. Diverse responses of phenology to global changes in a grassland ecosystem. Proc. Natl. Acad. Sci. USA 2006, 103, 13740-13744. [CrossRef] [PubMed]

18. Lan, B.Q.; Li, J.J.; Duan, Q.X. Chinese Tree Peony Encyclopaedia; China Science and Technology Press: Beijing, China, 2002.

19. Wei, X.L.; Kong, F.Z.; Zhang, Z.Y.; Zhang, C.Y. Long term forecast for peony florescence in Heze. Meteorol. Mon. 2001, 27, 55-57.

20. Wang, P.; Li, R.J.; Xu, H.Y. The forecasting of peony florescence based on multivariate regression analysis. Agric. Netw. Inf. 2008, 3, 139-142.

21. Zhang, F.; Xing, X.X.; Li, R.J.; Gai, S.P.; Zheng, G.S. A prediction model for florescence of tree peony based on soil temperature in Heze city of Shandong Province. Chin. J. Agrometeorol. 2008, 29, 87-89.

22. Wan, M.W.; Liu, X.Z. Phenological Observation Method in China; Science Press: Beijing, China, 1979.

23. Baltagi, B.H. Econometric Analysis of Panel Data, 3rd ed.; John Wiley\&Sons Ltd.: Chichester, UK, 2005.

24. Hsiao, C. Analysis of Panel Data; Cambridge University Press: Cambridge, UK, 2003.

25. Moulton, B.R. Random group effects and the precision of regression estimates. J. Econom. 1986, 32, 385-397. [CrossRef]

26. Moulton, B.R. Diagnostics for group effects in regression analysis. J. Bus. Econ. Stat. 1987, 5, $275-282$. [CrossRef]

27. Gao, T.M. The Analysis Method and Statistical Modelling of Econometrics: A Guidebook for Using EViews; Tsinghua University Press: Beijing, China, 2009.

28. Lorenz, E.N. Empirical Orthogonal Functions and Statistical Weather Prediction; Department of Meteorology, Massachusetts Institute of Technology: Cambridge, MA, USA, 1956.

29. Nash, J.E.; Sutcliffe, J.V. River flow forecasting through conceptual models part I-A discussion of principles. J. Hydrol. 1970, 10, 282-290. [CrossRef]

30. Cook, E.R.; Meko, D.M.; Stahle, D.W.; Cleaveland, M.K. Drought reconstructions for the continental United States. J. Clim. 1999, 12, 1145-1162. [CrossRef]

31. Sparks, T.H.; Jerffree, E.P.; Jeffree, C.E. An examination of the relationship between flowering times and temperature at the national scale using long-term phonological records from the UK. Int. J. Biometeorol. 2000, $44,82-87$.

32. Xu, Y.Q.; Lu, P.L.; Yu, Q. Impacts of climate change on the first-flowering dates of Robinica pseudoacacia. and Syringa amurensis. in China. J. Beijing For. Univ. 2004, 26, 94-97.

33. Jiang, J.F.; Liang, C.H.; Yang, H.; Zhang, Y.L.; Ding, W.K.; Yang, Y.L. Influence of temperature and precipitation on phenology of desert plant Haloxylon ammodendron and Cornulaca alaschanica in recent ten years. J. Arid Land Res. Environ. 2017, 32, 141-146.

34. Wang, H.J.; Dai, J.H.; Ge, Q.S. The spatiotemporal characteristics of spring phenophase changes of Fraxinus chinensis in China from 1952 to 2007. Sci. China Earth Sci. 2012, 55, 991-1000. [CrossRef]

35. Ge, Q.S.; Dai, J.H.; Zheng, J.Y.; Bai, J.; Zhong, S.Y.; Wang, H.J.; Wang, W.C. Advances in first bloom dates and increased occurrences of yearly second blooms in eastern China since the 1960s: Further phenological evidence of climate warming. Ecol. Res. 2011, 26, 713-723. [CrossRef]

36. Schwartz, M.D.; Ahas, R.; Aasa, A. Onset of spring starting earlier across the Northern Hemisphere. Glob. Chang. Biol. 2006, 12, 343-351. [CrossRef]

37. Zhu, K.Z.; Wan, M.W. Phenology; Science Press: Beijing, China, 1973.

38. Ge, Q.S.; Wang, H.J.; Dai, J.H. Simulating changes in the leaf unfolding time of 20 plant species in China over the twenty-first century. Int. J. Biometeorol. 2014, 58, 473-484. [CrossRef] [PubMed] 
39. Yang, F.Y.; Zhu, Y.J.; Liu, W.C. Occurrence rules and risk zoning of dry-hot wind in winter wheat producing areas of north China. J. Nat. Disast. 2013, 22, 112-121.

40. Chen, M.; Fu, B.P. Numerical study for foehn in east slope of TaiHang Mountain. Plateau Meteorl. 1995, 14, 443-450.

41. Chen, S.L.; Guo, Y.C.; Guo, K. Investigation Study on the Climate of Taihang Mountains and Luliang Mountains; Meteorology Press: Beijing, China, 1993.

42. Zhang, L.Y.; Li, N.; Liu, M. On the basic concept of Smarter Tourism and Its theoretical system. Tour. Trib. 2012, 27, 66-73.

43. Ma, L.A.; Fang, X.Q. Effects of global warming on seasonal tourism for the last 20 years in Beijing-A case study on the Peach flower stanza of Beijing Botanical Garden. Adv. Earth Sci. 2006, 21, 313-319.

44. Liu, J.; Li, Y.Y.; Liu, H.L.; Ge, Q.S.; Dai, J.H. Climate change and peach blossom viewing: Impact and adaptation. Geogr. Res. 2016, 35, 504-512.

45. Tao, Z.X.; Zhong, S.Y.; Ge, Q.S.; Dai, J.H.; Xu, Y.J.; Wang, H.J. Spatiotemporal variations in flowering duration of woody plants in China from 1963 to 2012. Acta Geogr. Sin. 2017, 72, 53-63.

(C) 2017 by the authors. Licensee MDPI, Basel, Switzerland. This article is an open access article distributed under the terms and conditions of the Creative Commons Attribution (CC BY) license (http:/ / creativecommons.org/licenses/by/4.0/). 